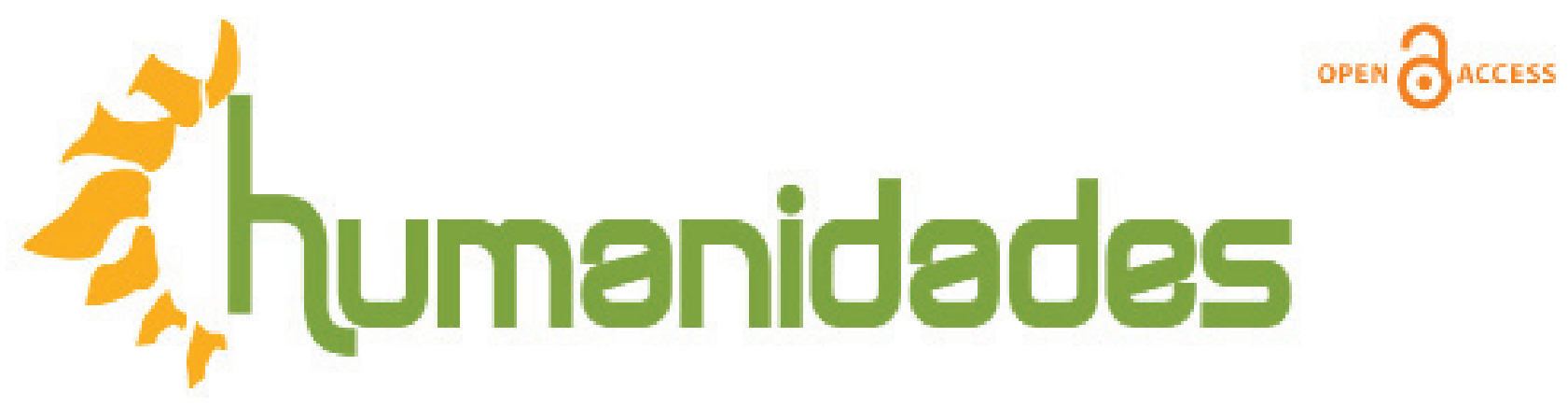

Revista de la Escuela de Estudios Generales, Universidad de Costa Rica

Enero-julio, 2019 •Volumen 9, número 1 • EISSN 2215-3934・pp. 1-22

Recibido: 1-Febrero-2018 Aceptado: 1-junio-2018

\title{
Capitalismo, derecho y libertad nunca fueron exactamente la misma cosa. Reflexiones en torno a una cuestión moderna y contemporánea
}

DOI: https://doi.org/10.15517/h.v9i1.35341

\section{Jorge Polo Blanco}

Doctor en Filosofía. Escuela de Diseño y Comunicación Visual (EDCOM) y Escuela Superior Politécnica del Litoral (EPSOL), Ecuador.

Correo electrónico: hiperbolik1983@hotmail.com

Todos los derechos reservados. Universidad de Costa Rica. Esta revista se encuentra licenciada con Creative Commons. Reconocimiento-NoComercial-SinObraDerivada 3.0 Costa Rica. Correo electrónico: humanidades@ucr.ac.cr/Sitio web: http: //revistas.ucr.ac.cr/index.php/ humanidades 


\section{Capitalismo, derecho y libertad nunca fueron exactamente la misma cosa. Reflexiones en torno a una cuestión moderna y contemporánea}

\section{Resumen}

En este trabajo queremos reflexionar sobre algunas polémicas teóricas que se han venido produciendo en torno a los conceptos de democracia política y sistema de libre mercado o, si se quiere, entre Estado de derecho y capitalismo. Nuestro objetivo es mostrarquelas relaciones entre dichos conceptosynociones son muchomás complejas y contradictorias de lo que se ha venido narrando apologéticamente a lo largo de los últimos doscientos años. En efecto, los teóricos del liberalismo económico siempre quisieron establecer que una genuina democracia política sólo podía darse allí donde imperase un orden económico liberal. Debemos problematizar este axioma e incluso indagar en la probable incompatibilidad de fondo entre un sistema de libre mercado completamente desregulado y un régimen político sustancialmente democrático.

\section{Capitalism, Law and Freedom Were Never Exactly the Same Thing. Reflections on a Modern and Contemporary Issue}

\begin{abstract}
In this paper we wish to reflect on theoretical controversies that have arisen around the concepts of political democracy and the free market system or, if one wishes, between a State based on the rule of law and capitalism. Our objective is to show that the relationships between these concepts and notions are much more complex and contradictory than suggested by the way that it has been narrated over the last two hundred years. Indeed, theorists of economic liberalism consistently wished to establish that a genuine political democracy could only occur wherever a liberal economic order prevailed. We must challenge this axiom and even inquire into the likely fundamental incompatibility between a completely deregulated free market system and an essentially democratic political regime.
\end{abstract}

Palabras clave: capitalismo, democracia, sistema de mercado, derecho, libertad

Keywords: capitalism, democracy, market system, law, freedom 
Capitalismo, derecho y libertad...

\section{Introducción}

Hoy, en la segunda década del siglo XXI, resulta muy pertinente movilizar una reflexión crítica en torno a una problemática absolutamente acuciante, perentoria, que afecta de manera nuclear a las sociedades occidentales contemporáneas; una problemática que remite, en última instancia, a la articulación profunda de las sociedades modernas desde hace al menos dos centurias. Hablamos de las relaciones que históricamente se han venido dando entre democracia política y sistema de libre mercado o, por formularlo con otra terminología, entre Estado de derecho y capitalismo. Dichas relaciones son mucho más complejas y contradictorias (es decir, evidencian mayores dosis de fricción) de lo que ciertos universos teóricos están dispuestos a admitir. En efecto, los teóricos del liberalismo económico siempre pretendieron consignar que una verdadera democracia política sólo podía darse allí donde imperase un orden económico de tipo liberal; ésa era su ecuación sagrada. Pero, a nuestro modo de ver, resulta crucial contradecir este dogma de fe, toda vez que una deconstrucción del relato dogmático del liberalismo económico nos servirá, quizás, para indagar en la posible —y probable - incompatibilidad de fondo entre un sistema de libre mercado (completamente independizado, esto es, enteramente desregulado) y un régimen político sustancialmente democrático. Algunos de los argumentos que serán empleados en este artículo ya quedaron plasmados en un trabajo que fue publicado en España (Polo, 2015a), pero ahora los matizaremos o reformularemos, dándoles otro acento y otro énfasis.

\section{Ilustración o capitalismo: ¿acaso son la misma cosa?}

Este decisivo problema estaba ya presente de una manera medular en la Escuela de Frankfurt, pues sus pensadores más destacados quisieron desvelar una irreductible aporía que recorría el interior de la racionalidad ilustrada. Su diagnóstico, en efecto, establecía que dicha racionalidad acabó produciendo opresivas concreciones institucionales. La reflexión de estos teóricos basculaba en torno a la sospecha de que la racionalidad espiritual y social abierta por la Ilustración estaba desde el principio preñada de una vocación económico-totalizadora que, de hecho, habría acabado verificándose de manera trágica en el devenir de las sociedades europeas. 
Como epítome de semejantes tesis podían concluir Adorno y Horkheimer, sin ambages, que "la Ilustración es totalitaria como ningún otro sistema" (2004, p. 78). La racionalidad de un aparato tecno-económico hipertrofiado y totalizador acabó absorbiendo dentro de su asfixiante dominio todos los resortes de la vida humana;este, y no otro, fue el resultado del devenir histórico del proyecto social de la modernidad, a juicio de los frankfurtianos.

Semejantes conclusiones, que acaban recelando de todo el proyecto ilustrado moderno, suponen una enmienda a la práctica totalidad de los resultados históricos de una racionalidad social reducida a sus aspectos más cosificadores y alienadores. En ese sentido, bien podían diagnosticar que "la razón misma se ha convertido en simple medio auxiliar del aparato económico omnicomprensivo" (Adorno y Horkheimer, 2004, p. 83). Una racionalidad meramente calculadora, instrumental, tecnocrática y economicista acabó imponiéndose de manera inexorable en el orden social occidental tras la apertura histórica de la racionalidad moderna; este era su cáustico diagnóstico. Pero hemos de preguntarnos si este desastroso desenlace se ha debido a la claudicación de un pensamiento ilustrado primigenio que, por efecto de ciertos procesos históricos, terminó siendo suplantado o, en todo caso, esterilizado (abortado, por causas ajenas a su propia consistencia interna); o si, como parecen insinuar los representantes de la Teoría Crítica, esa racionalidad cosificadora y alienante que acabó triunfando estaba ya incoada desde siempre en el proyecto político de la Ilustración. Resultará determinante ofrecer una respuesta a semejante disyuntiva porque, desde luego, no es lo mismo aseverar que la Ilustración "guardaba" todo el mal en sus entrañas (tesis frankfurtiana y, después, “posmoderna") que señalar, por el contrario, que el proyecto de la Ilustración fue socavado casi desde el comienzo por unas dinámicas económico-políticas que bloquearon toda posibilidad de realización efectiva de dicho proyecto. Quizás hubo, por expresarlo de otra manera, una "modernidad triunfante" (la capitalista) y una "modernidad derrotada o falseada" (la de la Ilustración). Y, si a pesar de todo, algo fue quedando de Ilustración resultó ser no gracias al capitalismo, sino a pesar del capitalismo. 
Capitalismo, derecho y libertad...

Para pivotar ahora hacia la otra posibilidad de la alternativa general que hemos planteado, por lo tanto, creemos muy oportuno tener en cuenta el trabajo teórico de los pensadores españoles Carlos Fernández Liria y Luis Alegre, los cuales mantienen una tesis opuesta a los postulados frankfurtianos. Cabe decir, piensan ellos, que el desarrollo del "proyecto político de la Ilustración" fue abortado por las exigencias de la economía capitalista casi desde su mismo nacimiento. Y, en todo caso, si el proyecto ilustrado ha sobrevivido en algunos de sus aspectos ha sido, precisamente, contra ese capitalismo. "Si el derecho quiere tener alguna oportunidad, tendrá que conquistarla contra la lógica del capital (...). El derecho sólo podrá tener alguna oportunidad real si logra desactivar por completo la lógica capitalista de producción" (Fernández y Alegre, 2010, p. 622). En efecto, el imperio de la legalidad y el orden del derecho pueden resultar, en ciertos momentos, instancias que frenan y estorban el despliegue de la acumulación capitalista, como de hecho ocurrió en muchas ocasiones. O, dicho de una forma inversa, el despliegue de la acumulación capitalista se puede consumar sólo a expensas de la desactivación más o menos explícita de un Estado de derecho verdaderamente tal.

Por lo tanto, resulta inconcebible postular que todo derecho es nada más que un dispositivo que se limita a reflejar, sublimar o racionalizar las exigencias del orden económico capitalista. En muchas, muchísimas ocasiones, fue nada más que eso. Es cierto; y lo fue más que en ningún otro lugar y momento, en los albores de la sociedad capitalista, cuando todavía estaba pendiente la intensa proletarización de una gran parte de la población, toda vez que en aquel entonces el entramado ejecutivo-legislativo-judicial había sido puesto en marcha para expropiar de mil maneras a la gente común. En este caso, evidentemente, el derecho funcionó como un dispositivo de racionalización de la violencia histórica perpetrada en los complejos procesos de expropiación de tierras comunales (aunque el propio Marx establece que aquella "acumulación originaria" fue, antes que otra cosa, un proceso brutal y violento de rapiña); el derecho, en cualquier caso, terminó contribuyendo de manera decisiva al afianzamiento de las nuevas relaciones sociales basadas en la propiedad "privada y exclusiva" de las tierras y en la mercantilización progresiva del mundo laboral En ese sentido, Adorno y Horkheimer sí habrían acertado parcialmente en su diagnóstico. Pero, y he aquí la clave del asunto, el derecho no siempre fue nada más que eso, como examinaremos a continuación. 
Como bien señaló Macpherson (1973, p. 148), la historia europea del siglo XIX (pero también la historia latinoamericana del siglo $\mathrm{XX}$, deberíamos añadir) puede mostrarnos que el "Estado liberal" y el "Estado democrático" no fueron exactamente la misma cosa; es más, si nos fijamos atentamente podremos comprobar que en muchos aspectos el segundo sólo pudo surgir contra el primero. El "Estado liberal" hubo de ser democratizado (es importante enfatizar el tiempo verbal), y lo fue principalmente por efecto de la presión progresiva de las masas populares y las clases trabajadoras, sindical y políticamente organizadas. Democratización en lo social, pero también en lo civil, debemos apostillar, ya que a través de dichas luchas se obtuvieron no sólo mejoras salariales, reducción de la jornada laboral, seguros por desempleo o la prohibición del trabajo infantil, sino también el sufragio universal, la libertad de reunión y asociación o una libertad de prensa más extensiva. Por ende, el "Estado liberal" no es necesariamente democrático porque, lo decimos de nuevo, hubo de ser democratizado (en lo social y en lo civil) a la fuerza.

Es verdad, como ha señalado Atilio Borón (2003, pp. 207-208), que en muchas ocasiones el pensamiento político de izquierda ha encallado en una cierta "estadolatría", en un fetichismo estatista; a través de una postura meramente defensiva o reactiva, que trataba de responder a esa ola neoliberal construida en base a una "satanización" de la esfera estatal, pudo recaer en aquella tesis hegeliana que contemplaba al Estado como el ámbito objetivamente reconciliador de la eticidad y la justicia. Pero, en cualquier caso, debemos comprender que el neoliberalismo, lejos de ser una mera "solución técnica", es antes que nada una teoría del Estado, esto es, una muy específica manera de comprender su naturaleza y sus funciones (Borón, 2003, p. 210). Y hemos de tener mucho cuidado con este asunto porque, a pesar de su retórica encendidamente anti-estatal, la filosofía neoliberal tiene muy claro que la acumulación capitalista necesita del Estado (mejor dicho, de un cierto tipo de Estado) para sobrevivir: 
Capitalismo, derecho y libertad...

El supuesto «antiestatismo» de los modernos cruzados del neoliberalismo es, en realidad, un frontal ataque a la democracia que las clases y capas populares supieron construir a pesar de la oposición y el sabotaje de los intereses capitalistas [...]. La propuesta neoliberal aparece obligándonos a optar entre el mercado y el Estado, como se sugiere con harta insistencia. Pero sabemos que ésa es una falsa disyuntiva, un mero artefacto ideológico y publicitario que en nada se compadece con el funcionamiento de los «capitalismos realmente existentes». En realidad el neoliberalismo remata en un dilema mucho más grave y, tal vez por eso, mucho menos explicitado: mercado o democracia. La democracia es el verdadero enemigo, aquello que está en el fondo de la crítica antiestatalista del neoliberalismo. No es al Estado a quien se combate, sino al Estado democrático. La ciega opción por el mercado es, a la vez, una preferencia en contra de los «riesgos» de la democracia. (Borón, 2003, p. 150)

El pensamiento neoliberal es plenamente consciente de los "riesgos" que un Estado democrático y de derecho, aunque conserve su carácter clasista, puede llegar a suponer para su proyecto si dentro de su estructura las clases populares conquistan importantes posiciones de mando. Por decirlo más sucintamente: al liberalismo económico más radicalmente consecuente siempre le molestó la "interferencia" de la democracia política (y más aún cuando esta también conllevaba exigencias de democratización socioeconómica).

Resulta muy pertinente, dentro del contexto polémico que aquí estamos tratando de esbozar, mencionar las tesis de Friedrich August von Hayek, uno de los "padres intelectuales" del neoliberalismo, quizás el más relevante junto a Ludwig von Mises. El austriaco reflexionó sobre las complejas relaciones que podían darse entre liberalismo económico y democracia, señalando que ambas realidades no podían quedar identificadas. Democracia y "orden económico liberal" no eran sinónimos, pensaba Hayek, y por ello pudo aseverar lo siguiente: "El liberalismo es, pues, incompatible con una democracia ilimitada" (2010, p. 91). Tan categórica y taxativa afirmación es crucial. 
En efecto, la democracia - aunque sea parlamentaria, garantista y constitucional, aunque respete la división de poderes y la producción de normas esté sujeta a normas, aunque cumpla todos esos requisitos - puede degenerar en tiranía, autoritarismo y esclavitud en el preciso momento en el que se decida intervenir en la libertad económica, esto es, en el momento mismo en el que se legisle para corregir o rectificar algún resultado producido por la "espontaneidad del mercado".

Para ilustrar lo anterior, Hayek ponía un ejemplo, muy significativo, de vulneración del "orden liberal" a manos de la "democracia ilimitada", como él la denomina. "Más dudosa aún es la compatibilidad de la concepción liberal de la igualdad con otra medida que sin embargo obtuvo un amplio apoyo en los círculos liberales. Se trata del impuesto progresivo sobre la renta como medio para alcanzar una redistribución de la renta a favor de las clases más pobres" (2010, p. 90). El hecho de que un liberalismo económico consecuente, llevado hasta sus últimas consecuencias, no pueda ni deba permitir una intervención política de corte fiscal en la distribución de la renta (por tímida que esta sea), conduce a Hayek a recelar abiertamente de la compatibilidad de un verdadero orden liberal con la democracia porque, en muchas ocasiones, la democracia requiere — para seguir siendo talintervenir en los "asuntos económicos". Bobbio, algún tiempo después, abundaría en esa misma tesis: "Un Estado liberal no es por fuerza democrático: más aún, históricamente se realiza en sociedades en las cuales la participación en el gobierno está muy restringida, limitada a las clases pudientes. Un gobierno democrático no genera forzosamente un Estado liberal" (1989, p. 7). Evidentemente, los avances en la extensión del sufragio universal y los procesos de empoderamiento popular fueron cuajando y, con ello, se fueron introduciendo modulaciones, correcciones o restricciones de los ámbitos de la "libertad económica", siendo así que, y en eso sí tenía razón Hayek, los avances de la democratización social pueden mermar la estabilidad, viabilidad y la consistencia de un Estado estrictamente liberal (liberal en lo económico, se entiende).

Siguiendo las ineludibles y certeras tesis de Karl Polanyi (2003), podemos entender que el desarrollo de una esfera económica cada vez más independiente y autónoma -inédito fenómeno en la historia de las civilizaciones humanas, toda vez que sólo podemos hallarlo en la modernidad industrial europea (Dumont, 1999) — conlleva una flagrante ausencia de control político democrático sobre todos aquellos aspectos vitales del orden social que tienen que ver con la organización del trabajo y el acceso a los bienes. 
Capitalismo, derecho y libertad...

Y si todos los aspectos vitales del orden social quedan entregados a un mecanismo mercantil crecientemente autónomo, resulta entonces que la democracia entendida en un sentido liberal es compatible con las mayores dosis concebibles de expoliación, inequidad y exclusión.

En efecto, el liberalismo económico es una doctrina que entiende que el espacio del mercado es, de forma inherente, un espacio de libertad en el que los sujetos jurídicamente iguales firman contratos e intercambian libremente capacidades y trabajos. Por lo tanto, dicho liberalismo (liberalismo económico, insistimos) no puede concebir que ese espacio del mercado es en verdad un mecanismo institucional en el que se dirimen y juegan los aspectos más vitales y sustantivos de la comunidad humana; un espacio, el del mercado, en el que además aparecen múltiples relaciones de poder, desequilibrios sociales y explotación. Por lo tanto, entender la democracia como una forma de liberar cada vez más al mecanismo del mercado en su expansión irrestricta y en su dinámica autónoma supone entender que dicha democracia apenas puede responsabilizarse de los ámbitos más decisivos y vitales del orden social; semejante modelo de democracia, que lo deja todo al albur de los "mercados libres", supone entender que las instituciones públicas deben desentenderse de los aspectos más acuciantes y determinantes de la vida cotidiana de la gente común. En ese sentido, la democracia liberal es una democracia mínima y de alcance limitado, puesto que sus prerrogativas y responsabilidades apenas pueden intervenir en el juego de esa esfera económica cada vez más autónoma (Wood, 2000).

Debemos afirmar algo que, para muchos teóricos, podría resultar inconcebible o inasimilable: liberalismo económico y liberalismo político no son la misma cosa; no siempre van de la mano e, incluso, en múltiples ocasiones aparecen como incompatibles. Tienen toda la razón Laval y Dardot (2013) cuando advierten que la hegemonía absoluta de la racionalidad neoliberal, en lo discursivo y en lo institucional, no sólo pone en entredicho la "tercera fase" de las olas democratizadoras, eso es, la fase en la que quedan consolidados los derechos sociales y laborales de la ciudadanía, sino que el avance irrestricto de la racionalidad liberal arruina, además, las primeras consolidaciones formalmente democráticas en el orden civil y jurídico. 
Por ello, tampoco la crítica de un cierto marxismo a la "democracia formal" expresa con suficiencia la gravedad del asunto, toda vez que incluso los propios fundamentos de una democracia meramente liberal ( $\sin$ entrar siquiera en el asunto del desmantelamiento del Estado social) están quedando interrumpidos. La gobernanza neoliberal no es, por lo tanto, democrática en la forma y antidemocrática en los hechos. El problema es más hondo, puesto que ya no es democrática en absoluto, ni siquiera en un sentido reductivamente formal (Laval y Dardot, 2013, p. 396). Y cuando un sistema económico desquiciado e incontrolable empieza a colisionar incluso con el modelo democrático más estrechamente formal y procedimental asistimos, entonces, a una modificación sustancial de todas las coordenadas políticas precedentes.

\section{Derecho y economía de libre mercado}

Sostenemos, por lo tanto, que el derecho y la economía de libre mercado no son la misma cosa. ¿Por qué podemos decir algo así? Pensemos que si la lógica capitalista, una vez la economía industrial de mercado resultó articulada y desarrollada con plenitud, quedase liberada de toda restricción externa (esto es, si operase sin sometimiento alguno al orden jurídico-político) conllevaría una situación de absoluta miseria para las masas expropiadas y unas condiciones materiales de vida insufribles para una gran parte de la población trabajadora; unas condiciones, en cualquier caso, radicalmente incompatibles con todo concepto de ciudadanía. Dicen, de nuevo, Fernández y Alegre:

Una vez expropiadas las condiciones de existencia, todo el mundo necesita recurrir al mercado para adquirir los bienes de subsistencia y, para ello, necesita un puesto de trabajo. Por lo tanto, la existencia de una masa de desempleados (a la que Marx se refiere como «ejército industrial de reserva» y la economía «burguesa» como «tasa natural de desempleo») garantiza que haya siempre gente dispuesta a trabajar incluso por salarios algo más bajos que los existentes para, así, por lo menos tener un empleo con el que obtener algún salario en vez de estar en paro. Ahora bien, el hecho de que esa masa de desempleados sea estructuralmente necesaria implica que no importa lo bajos que sean ya los salarios: siempre habrá alguien a quien le interese más trabajar (aunque sea a cambio de un salario todavía menor) que quedar desempleado. En estas condiciones - a menos que se produzca alguna intervención externa y ajena a la lógica del mercado, como el establecimiento de salarios mínimos o la exigencia de la negociación colectiva - resulta claro que los salarios tenderán a ajustarse a los bienes mínimos de subsistencia. (2010, p. 400) 
Capitalismo, derecho y libertad...

Se trata, en efecto, de que el derecho imponga coactivamente unos límites a la voracidad ilimitada del capital, en lo que a su apropiación de la fuerza de trabajo se refiere; es decir, de imponer unos límites a esa insaciabilidad inherente al capital que, dejado a su libre desenvolvimiento, tendería a apropiarse de plustrabajo durante las veinticuatro horas del día. He ahí la terrible hybris inherente a un sistema económico semejante (Polo, 2015b). Porque si algo define a dicha lógica es su tendencia irreprimible (esto es, estructural) a apropiarse desmedida y desproporcionalmente de una cantidad siempre creciente de trabajo humano o, dicho de otra forma, una propensión desmedida y desproporcionada a estirar la explotación de la fuerza de trabajo hasta los límites mismos de lo humanamente soportable. No se debe olvidar, por supuesto, la propensión igualmente desmedida y desproporcionada del capital a explotar sin límites la naturaleza; una tendencia que también debe ser sujetada, regulada o prohibida a través del derecho.

Por lo tanto, si el derecho fue durante los seculares procesos históricos de expropiación y proletarización una herramienta criminal y un dispositivo racionalizador y legitimador de inenarrables violencias históricas, si eso fue indudablemente así durante mucho tiempo, no podemos perder de vista que una vez el capitalismo se institucionalizó como el modo económico dominante, el derecho también quedó convertido en el único dique de contención al que podían agarrarse las clases populares y el pueblo trabajador, pues sólo construyendo un derecho social anticapitalista (plasmado en leyes fabriles relativas a las condiciones higiénicas y de seguridad en el lugar de trabajo, en leyes de salarios mínimos, en leyes sobre la fijación de la duración máxima de la jornada laboral, en leyes sobre la prohibición del trabajo infantil) podían las clases populares arrancarle a la lógica del capital unas condiciones de vida más dignas y un mundo más habitable.

No pretendemos sostener que la explotación específicamente capitalista sea una simple realidad jurídica. La explotación no es un mero desajuste jurídico o una mera ausencia de ley, puesto que incluso dentro de un marco jurídico que sea densamente protector en lo social y en lo laboral el mecanismo interno de dicha explotación puede subsistir desde un punto de vista estructural. 
Ahora bien, aunque el mecanismo de la explotación capitalista conserve su estatuto ontológico dentro de cualquier Estado de derecho, por muy avanzado que este sea en cuestiones de protección social, ello no implica que capitalismo y derecho sean la misma cosa. Es más, el derecho en muchas ocasiones ha podido desplegar sus potencias y sus efectos contra la lógica interna del sistema capitalista. Immanuel Wallerstein, una de las figuras que con mayor profundidad ha estudiado el desarrollo histórico del capitalismo, supo aprehender la envergadura de esta sencilla verdad: el Estado ha sido "el instrumento por excelencia de los reformistas para ayudar a la gente a ir sobreviviendo" (1996, p. 6). Esa no ha sido en absoluto la única función cumplida por el Estado, desde luego, ni siquiera su función principal. Pero, concluye Wallerstein, las múltiples luchas de las clases populares por mejorar sus condiciones de existencia (o, directamente, por sobrevivir) se fueron dirigiendo, en buena medida, a lograr que los Estados actuasen de determinada manera y cumpliesen ciertas obligaciones.

Rousseau, en un alarde de realismo, comprendió bien la enjundia de este asunto: "El mayor mal está ya hecho cuando existen pobres que defender y ricos que contener" (1985, p. 28). Pero, a renglón seguido, reconoce que "uno de los más importantes asuntos del gobierno consiste en prevenir la extrema desigualdad de las fortunas" (p. 28). Y, en efecto, si las clases populares y trabajadoras pudieron en alguna medida doblarle el brazo a la racionalidad inmanente de la acumulación capitalista fue conquistando posiciones dentro del aparato estatal para, desde ahítejer legislación socialmente protectora y construir derecho laboral. El Estado Moderno, que en muchas ocasiones funcionó como una terrible maquinaria coactiva al servicio de las clases económicamente dominantes, fue también un instrumento popular y plebeyo esencial a la hora de dignificar las condiciones de vida de las masas desposeídas. Toda la historia de las luchas plebeyas y obreras, todas las conquistas sindicales y sociales derivadas de esa cruenta y secular batalla, pueden ser consideradas como otras tantas victorias que el derecho pudo arrancarle a la lógica del capital (Thompson, 2012). Puede, en efecto, que en los albores de la sociedad capitalista el derecho no hubiese sido más que una maquinaria violenta diseñada y construida para expropiar a las masas populares y permitir de ese modo la acumulación originaria de capital. Pero que el derecho no sólo llegó a ser eso lo demostraría con creces la dura trayectoria del movimiento obrero (Domènech, 2003). 
Capitalismo, derecho y libertad...

Evgeny Pasukanis, uno de los más relevantes juristas soviéticos, en 1924 escribía una elaborada concepción de las relaciones entre derecho y capitalismo en la que no podía dejar de señalar que la forma-mercancía era la matriz misma de la que emergía toda la configuración del derecho moderno, que de esa manera quedaba caracterizado como "derecho burgués". Según tales premisas, toda forma jurídica per se hunde sus raíces en la forma-mercancía y en el intercambio de equivalentes, de tal manera que, y esa es la tesis fundamental de Pasukanis, el derecho es esencialmente la forma mixtificada de una relación social muy específica, a saber, la capitalista (Pasukanis, 1976). Si hemos traído a colación este ejemplo paradigmático de teorización soviética del derecho como construcción social "inherentemente burguesa" es porque creemos que, a tenor de lo que veíamos hace un momento, resultaría harto insuficiente considerar que todo el derecho moderno es, en sí mismo, nada más que un dispositivo burgués puesto al servicio de las exigencias del capital. Fernández y Alegre, precisamente, responderían lo siguiente a una concepción como la de Pasukanis:

Una cosa es que el derecho no funcione bajo condiciones capitalistas de producción, o que funcione de forma tan defectuosa que se convierta en un mero instrumento de dominación para las élites más poderosas, y otra cosa bien distinta es que el derecho tenga que ser eso necesariamente. La Ilustración no tiene por qué cargar con aquello que el capitalismo ha hecho de ella. Si bajo condiciones capitalistas de producción aparece convertido en un instrumento dictatorial de poder, no es porque al derecho le corresponda ser eso, sino porque bajo esas condiciones el derecho resulta impracticable. Lo que se impone no es, por tanto, decir que puesto que eso ocurre bajo el capitalismo, el derecho es eso en realidad, sino más bien que en esa realidad el derecho es imposible y que aquello a lo que se llama derecho no es el derecho, sino una mera apariencia de derecho. Lo que se impone no es denunciar el derecho, sino denunciar al capitalismo porque, entre otras cosas, hace imposible que el derecho funcione bien (...). Y, en efecto, lo que hay que sacar a la luz es el carácter intolerable del capitalismo y no ningún reverso tenebroso de ningún lado oscuro amenazante del derecho, la razón occidental o la ciudadanía. (2007, p. 144) 
El derecho no es un dispositivo intrínsecamente burgués, en suma. ¿Por qué? Porque el derecho también puede ser (y de hecho ha sido) un conjunto de "pautas extrañas" introducidas en el interior del mercado autorregulado a través de las huelgas exitosas o a través de un cuerpo legislativo emanado de un parlamento eventualmente ocupado por una mayoría de representantes de la clase trabajadora; estaríamos hablando de unas "coacciones" parlamentarias, legislativas y jurídicas (democráticas, en suma) impuestas al funcionamiento libre y autónomo del mecanismo institucional del mercado. O, dicho con otras palabras, estaríamos hablando de victorias del derecho sobre el capital que se traducirían en la dignificación de la existencia material y cultural de las clases populares. Unas (costosas) victorias que, precisamente por ser tales, muestran con su sola facticidad que derecho y capitalismo no son lo mismo.

Desde esta perspectiva, el derecho formal moderno del que hablaba Max Weber (1983), pese a haber auspiciado y protegido secularmente unas relaciones contractuales y de propiedad evidentemente óptimas para el despliegue del "negocio burgués", no se identificaría de manera consustancial con el modo de producción capitalista. Las formas modernas del derecho, a través de su plasmación y elaboración en la tradición política republicana, podrían entrar (y así fue en numerosas ocasiones) en abierto conflicto material con el automatismo del sistema económico capitalista. Porque, en última instancia, sólo un vaciado sustancial de ese contenido material del derecho republicano puede mantener la fementida apariencia de que la forma-derecho y el capitalismo son una y la misma cosa.

Pero cuidado, porque derecho y democracia tampoco son nociones idénticas o indistinguibles. Esta cuestión, sin duda, desborda los límites de nuestro pequeño estudio; pero, en cualquier caso, queremos consignar tal diferencia, siquiera sea a modo de apéndice complementario. Y para explicarla, diremos simplemente que hay determinadas cuestiones que son indecidibles. ¿Qué quiere esto decir? Que hay decisiones que no se pueden tomar, por muy mayoritariamente respaldadas que se hallen; por ejemplo, una mayoría social no puede (con arreglo a derecho) decidir el exterminio de una minoría (étnica o sexual). Tal decisión puede cumplir el principio democrático (esto es, contar con el apoyo explícito de un sector cuantitativamente mayoritario de la población) y, sin embargo, constituir una decisión contraria al derecho (por ser incompatible con los derechos más elementales de cualquier ser humano). 
Capitalismo, derecho y libertad...

Por lo tanto, si anteriormente señalábamos (siendo el objeto expreso de nuestro trabajo) que capitalismo y derecho no son exactamente la misma cosa (nunca lo fueron), ahora añadimos que derecho y democracia tampoco son exactamente lo mismo.

\section{Republicanismo democrático y economía privada}

¿Cómo concibe la tradición republicana las relaciones entre democracia, derecho y economía? Podemos acudir, de manera paradigmática, a los planteamientos de Robespierre. El proyecto jacobino (un proyecto político y social que no triunfó, hemos de recordarlo de manera insistente, pues fue abortado mediante una contrarrevolución orquestada por las facciones políticas de los propietarios) otorgaba al poder legislativo no sólo la capacidad (y el deber) de redistribuir la riqueza a través de una fiscalidad progresiva, sino la potestad de limitar el ejercicio del derecho de propiedad (y asimismo la posibilidad de intervenir en la esfera del comercio) en todos aquellos casos en los que el poder económico privado entrara en abierta contradicción con los principales derechos del hombre, entre los cuales se hallaba un "derecho a la subsistencia" que debía ser garantizado por la República, haciendo esta lo que tuviera que hacer e interviniendo donde tuviese que intervenir. Ninguna propiedad es tan sagrada que no pueda ser intervenida si ello se requiere para salvaguardar algún interés común superior, valdría decir; y la libertad de comercio podrá permitirse siempre y cuando esta no ponga en riesgo la supervivencia misma de una parte sustancial de la comunidad. "Toda especulación mercantil que hago a expensas de la vida de mi semejante no es tráfico, es bandidaje y fratricidio" (Robespierre, 2005, p. 158). Robespierreno duda en poner decididamente el denominado "derecho a la existencia" por encima del derecho a la propiedad privada; esta puede ser intervenida, regulada y reglamentada si con ello puede garantizarse aquel derecho primordial. 
No basta con tener ciudadanos y con protegerlos; es preciso además cuidar de su subsistencia (...). Este deber no consiste, como pudiera parecer, en llenar los graneros de los particulares y en dispensarles de trabajar, sino en mantener la abundancia a su alcance de tal modo que para adquirirla el trabajo sea siempre necesario y jamás inútil. (1985, p. 34)

El deber de un gobierno verdaderamente republicano consiste en garantizar que los hombres puedan obtener unas condiciones materiales de vida lo suficientemente dignas, rehuyendo todo orden social en el que un trabajo extenuante sólo sirva para malvivir en los umbrales de la miseria. Porque, dadas ciertas condiciones y relaciones materiales en el orden social, decretar la máxima libertad económica puede conllevar situaciones de verdadera tiranía y calamidad social.

Sacralizar la "libertad" de comercio y la "libre" disposición de la propiedad privada cuando el ejercicio sin trabas de dichas libertades implica una intensificación de la miseria pública es, en realidad, hacer apología de la subyugación material de muchos ciudadanos que, por ello mismo, dejan de ser tales. "Yo os denuncio a los enemigos del pueblo y me respondéis: dejadlos hacer" (Robespierre, 2005, p. 161). La consigna “dejar hacer, dejar pasar" (laissez faire, laissez passer), virulentamente esgrimida por los fisiócratas y utilizada ulteriormente por toda la tradición librecambista, puede alimentar y reproducir una situación social materialmente incompatible con la libertad real de todos los miembros de la comunidadpolítica. La independencia civil, condición sine qua non de una verdadera ciudadanía, sólo puede lograrse a través de unas condiciones materiales de vida dignas; y para conseguir esto último la República puede y debe intervenir muchas de esas "libertades" y propiedades de los dueños de la economía. Pero este programa republicano-jacobino, y con él la esencia del proyecto ilustrado, resultaron derrotados (Gauthier, 1992; Pisarello, 2011). 
Capitalismo, derecho y libertad...

\section{Las condiciones materiales de la libertad}

El liberalismo económico siempre imaginó que el ámbito del mercado es, de forma inherente, un espacio de genuina libertad en el que sujetos jurídicamente iguales firman contratos e intercambian libremente capacidades y trabajos. Por lo tanto, dicho liberalismo nunca pudo entender que el espacio mercantil constituye un mecanismo institucional en el que se dirimen y juegan los aspectos más vitales y sustantivos de la comunidad humana y en el que, a su vez, se dan de forma inevitable relaciones asimétricas, desequilibrios brutales y explotación y acumulación de mucho poder en pocas manos. En definitiva, el liberalismo económico nunca fue capaz de comprender que el mercado constituye en última instancia un campo de fuerzas en tensión en el que no todos los participantes intervienen con la misma proporción de capacidad negociadora.

Y, por ello mismo, entender la democracia como una forma de "liberar" cada vez más al mecanismo del mercado en su expansión irrestricta y en su dinámica autónoma supone entender que dicha democracia apenas puede responsabilizarse de los ámbitos más decisivos y vitales del orden social y de los aspectos más acuciantes y determinantes de la vida cotidiana de la gente común. En ese sentido, la democracia estrictamente liberal es una democracia mínima y de alcance limitado, toda vez que sus prerrogativas y responsabilidades apenas pueden intervenir en el juego decisivo de esa esfera económica cada vez más autónoma.

De manera radicalmente opuesta, y como veíamos hace un momento, la tradición republicana entiende que la libertad precisa unas condiciones materiales, y estas sólo pueden emerger allí donde una institucionalidad pública regula e interviene en el proceso económico, esto es, allí donde la organización del sustento material de la comunidad es estructurada con arreglo a criterios vinculados a la protección social, destruyendo la tiranía del sistema de mercado y no acatando como inexorable e inmodificable la legalidad económica de dicho sistema. Impedir, con el derecho y la norma (esto es, con una regulación política democrática), que elibre mercado determine jornadas laborales de catorce horas; prohibir que trabajen niños de ocho años; obligar a las empresas a guardar las medidas pertinentes de seguridad en los 
obligar a las empresas a guardar las medidas pertinentes de seguridad en los centros de trabajo; no permitir que personas enfermas o mujeres embarazadas sean despedidas por esa misma circunstancia; imposibilitar todos estos atentados contra las más elementales condiciones de la dignidad, en definitiva, implica generar libertad material desde la institucionalidad pública. Y todos los intentos por avanzar hacia mayores cotas de democratización socioeconómica habrán de visibilizar y evidenciar la más que discutible (y acaso fementida) identificación liberal de libertad (de toda libertad posible) con la libertad económica de los dueños del capital.

Desde esa misma tradición republicana caber ser muy crítico con el concepto de "libertad negativa" esgrimido por los teóricos del liberalismo económico (Pettit, 1999). Pues desde aquella tradición se evoca una institucionalidad que ha de hacer prevalecer algunos derechos por encima de la libertad de comercio, siendo así que algunos de los derechos sociales más esenciales tienen que ver, por ejemplo, con esa mercancía tan especial llamada "fuerza de trabajo"; en efecto, la garantía de unas condiciones laborales dignas habrá de producirse a expensas de la libre determinación mercantil del precio del trabajo. Democratizar la vida económica y dignificar el mundo laboral implica, en ese sentido, violentar (regular, modular, reglamentar) la libertad del mercado. Es decir, para promover y proteger la libertad material de las mayorías sociales es preciso, no cabe duda, desvirtuar la libertad económica, interviniéndola o incluso desactivándola si fuera preciso.

La concepción republicana de la libertad hará hincapié en una libertad sustantiva y material que no se limitará a un vacío “dejar hacer”, y menos aun cuando ese "dejar hacer" equivale a poner el destino del orden social en manos de unas dinámicas de acumulación y desposesión generadoras de explotación, anomia y descomposición social (Harvey, 2003). La construcción de una democracia industrial más potente o, por decirlo con otras palabras, el avance hacia una institucionalidad socioeconómica más democratizada, implica que ciertas libertades materiales y sustantivas de las mayorías sociales tengan que lograrse y protegerse interviniendo algunas libertades económicas; y esto es precisamente lo que los doctrinarios del liberalismo económico no podían y no pueden asumir (Raventós, 2007). 
Capitalismo, derecho y libertad...

Postulando un concepto de libertad meramente negativo, en efecto, el liberalismo económico apenas puede concebir un significado de la libertad distinto al consistente en una mera "no-coacción" sobre el individuo por parte de poderes externos (Berlin, 2001). La tradición republicana defiende que esa libertad negativa puede ser necesaria, pero nunca suficiente, porque la libertad también requiere de ciertas condiciones materiales de existencia $\mathrm{Y}$ es por ello que la propuesta de una libertad materialmente garantizada por los poderes públicos entenderá que la llamada "libertad económica" puede implicar, en su autónomo desenvolvimiento, una dominación brutal de ciertos poderes privados sobre la mayoría social, sobre la vida de la gente común. Decretar la pura libertad económica, en un contexto de economía de mercado, puede derivar en un menoscabo absoluto de las condiciones materiales de vida imprescindibles para que la gente común pueda acceder siquiera a una libertad civil digna de tal nombre. Esa genuina libertad civil, materialmente sustentada y garantizada, quizás sólo pueda tener ocasión de realizarse contraviniendo buena parte de los postulados del liberalismo económico (Skinner, 1998).

\section{A modo de breve conclusión}

Los teóricos del liberalismo económico siempre quisieron establecer que una verdadera democracia política sólo podía darse allí donde imperase un orden económico liberal. Esto es, que la verdadera libertad humana sólo podía germinar dentro de una economía de mercado bien desarrollada. Pero, enfrentándonos críticamente a ese dogma, hemos querido poner en valor la tesis opuesta.

Porque, en efecto, la democratización social en muchas ocasiones sólo puede avanzar contra el sistema de mercado. De manera paradigmática, un avance sustancioso en la legislación fabril y laboral (leyes sobre salarios mínimos y duración de la jornada laboral, de salubridad en el centro de trabajo, de baja remunerada por enfermedad, embarazo o paternidad/maternidad, prohibición del trabajo infantil), la implementación de sistemas educativos y sanitarios de carácter público-estatal (de alcance universal), pero también los avances en legislación fiscal (establecimiento de impuestos progresivos a la renta con fines redistributivos), todas esas construcciones institucionales y legislativas, en definitiva, han supuesto elementos decisivos de democratización social y democratización económica; elementos, en suma, que caminan en la dirección de una mayor "democracia industrial", como se decía en otro tiempo (Webb, 1965). 
Por lo tanto, todos esos avances sociales y jurídicos deben entenderse como "conquistas de la libertad" obtenidas contra la lógica liberada del sistema de mercado. Esos avances democratizadores, que van construyendo nuevos espacios de dignidad civil y libertad material (nuevos espacios de ciudadanía, en definitiva), se sustancian y concretan mediante "interrupciones" o "suspensiones" de la lógica libre de los mercados.

\section{Referencias}

Adorno, T. y Horkheimer, M. (2004). Dialéctica de la Ilustración. Madrid: Trotta.

Berlin, I. (2001). Dos conceptos de libertad y otros escritos. Madrid: Alianza.

Bobbio, N. (1989). Liberalismo y democracia. México: Fondo de Cultura Económica.

Borón, A. (2003). Estado, capitalismo y democracia en América Latina. Buenos Aires: CLACSO.

Domènech, A. (2003). El eclipse de la fraternidad. Una revisión republicana de la tradición socialista. Barcelona: Crítica.

Dumont, L. (1999). Homo aequalis. Génesis y apogeo de la ideología económica. Madrid: Taurus.

Fernández, C. y Alegre, L. ( 2007). Educación para la Ciudadanía. Democracia, capitalismo y Estado de Derecho. Madrid: Akal.

Fernández, C. y Alegre, L. (2010). El orden de El Capital. Madrid: Akal.

Gauthier, F. (1992). Triompheet mort du droit naturel en Révolution. 1789-17951802. París: PUF. 
Capitalismo, derecho y libertad...

Harvey, D. (2003). The New Imperialism. Oxford: Oxford University Press.

Hayek, F. A. (2010). Principios de un orden social liberal. Madrid: Unión Editorial.

Laval, C. y Dardot, P. (2013). La nueva razón del mundo. Ensayo sobre la sociedad neoliberal. Barcelona: Gedisa.

Macpherson, C. B. (1973). Democratic theory. Essays in retrieval. Oxford: Oxford University Press.

Montesquieu. (1993). Del espíritu de las leyes. Madrid: Tecnos.

Pasukanis, E. B. (1976). Teoría general del derecho y marxismo. Barcelona: Labor.

Pettit, P. (1999). Republicanismo. Una teoría sobre la libertad y el gobierno. Barcelona: Paidós.

Pisarello, G. (2011). Un largo Termidor. La ofensiva del constitucionalismo antidemocrático. Madrid: Trotta.

Polanyi, K. (2003). La gran transformación. Los orígenes políticos y económicos de nuestro tiempo. México: Fondo de Cultura Económica.

Polo, J. (2015a). República y economía. Un análisis de la relación siempre conflictiva, y acaso antagónica en el límite, que se da entre un sistema económico de libre mercado y la institucionalidad política democrática. Sociología Histórica, (5), 471-508.

Polo, J. (2015b). La economía tiránica. Sociedad mercantilizada, dictadura financiera y soberanía popular. Madrid: Carpe Noctem.

Raventós, D. (2007). Las condiciones materiales de la libertad. Barcelona: El Viejo Topo. 
Robespierre, M. (2005). Discurso sobre las subsistencias y el derecho a la existencia en la Convención, 2 de diciembre de 1792. En Y. Bosc, F. Gauthier y S. Wahnich (Eds.), Por la felicidad y por la libertad. Discursos (pp. 154-163). Barcelona: El Viejo Topo.

Rousseau, J.-J. (1985). Discurso sobre la economía política. Madrid: Tecnos.

Skinner, Q. (1998). Liberty before Liberalism. Cambridge: Cambridge University Press.

Thompson, E. P. (2012). La formación de la clase obrera en Inglaterra. Madrid: Capitán Swing.

Wallerstein, I. (1996). Después del liberalismo. México: Siglo XXI.

Webb, S. (1965). Industrial Democracy. Nueva York: Augustus M. Kelley.

Weber, M. (1983). Historia económica general. México: Fondo de Cultura Económica.

Wood, E. M. (2000). Democracia contra capitalismo. La renovación del materialismo histórico. México: Siglo Veintiuno. 